\title{
Dysregulated transcriptional and post-translational control of DNA methyltransferases in cancer
}

\author{
Ruo-Kai Lin ${ }^{1,3,4}$ and Yi-Ching Wang ${ }^{2 *}$
}

\begin{abstract}
Cancer is a leading cause of death worldwide. Aberrant promoter hypermethylation of CpG islands associated with tumor suppressor genes can lead to transcriptional silencing and result in tumorigenesis. DNA methyltransferases (DNMTs) are the enzymes responsible for DNA methylation and have been reported to be over-expressed in various cancers. This review highlights the current status of transcriptional and post-translational regulation of the DNMT expression and activity with a focus on dysregulation involved in tumorigenesis. The transcriptional up-regulation of DNMT gene expression can be induced by Ras-c-Jun signaling pathway, Sp1 and Sp3 zinc finger proteins and virus oncoproteins. Transcriptional repression on DNMT genes has also been reported for p53, RB and FOXO3a transcriptional regulators and corepressors. In addition, the low expressions of microRNAs 29 family, 143, 148a and 152 are associated with DNMTs overexpression in various cancers. Several important post-translational modifications including acetylation and phosphorylation have been reported to mediate protein stability and activity of the DNMTs especially DNMT1. In this review, we also discuss drugs targeting DNMT protein expression and activation for therapeutic strategy against cancer.
\end{abstract}

Keywords: DNA methyltransferase, Cancer, Tumor suppressor gene, Transcription, Post-translational modifications

\section{Introduction}

Cancer is a leading cause of death worldwide, accounting for 8.2 million deaths in 2012 [1]. The process of tumorigenesis needs to be initiated and promoted by molecular abnormalities including oncogenes activation and tumor suppressor genes (TSGs) inactivation [2]. Methylation of CpG islands is one of the epigenetic modifications in mammalian genome that modulates gene expression without changes in the DNA sequence [2]. Aberrant promoter hypermethylation of CpG islands associated with TSGs can lead to transcriptional silencing and result in tumorigenesis. DNA methylation is frequently not restricted to a single $\mathrm{CpG}$ island but affects multiple independent loci, reflective of a widespread deregulation of DNA methylation pattern in different types of tumors $[3,4]$. Development of genome-wide high-throughput technologies has facilitated the identification of global DNA methylation pattern [5,6]. For example, genomic screening of 98 different primary human tumors has

\footnotetext{
* Correspondence: ycw5798@mail.ncku.edu.tw

${ }^{2}$ Department of Pharmacology and Institute of Basic Medical Sciences,

National Cheng Kung University, No.1, University Road, Tainan 70101, Taiwan Full list of author information is available at the end of the article
}

revealed that on an average there exist about 600 aberrantly methylated CpG islands in each tumor [7]. In addition, an increase of methylation variability may contribute to tumor heterogeneity [8]. Collectively, dysregulation of DNA methylation is apparently one of the major barriers to effective cancer diagnosis and treatment in different types of cancer.

Epigenetic disorders give rise to several significant human diseases including various cancers, neuron disorder, psychosis, and cardiovascular diseases, many of which are associated with altered expression and activity of DNA methyltransferases (DNMTs) [9-13]. DNMTs are the enzymes responsible for DNA methylation through transfer of methyl group to cytosine residue of CpGs [2]. Five types of DNMTs have been identified, viz. DNMT1, 2, 3A, 3B, and 3L. DNMT1 comprises a large $\mathrm{N}$-terminal domain with regulatory function and a smaller $\mathrm{C}$-terminal catalytic domain [14]. The regulatory domain harbors different motifs and is involved in the intracellular delivery and regulation of catalytic activity of DNMT1. DNMT1 has been shown to prefer hemimethylated over unmethylated DNA 30- to 40-fold in vitro [15-17]. It is referred to as a "maintenance" methyltransferase and is the primary 
enzyme responsible for copying the methylation patterns after DNA replication. DNMT1 localizes to replication foci and interacts with PCNA, a processivity factor for DNA replication complex [18]. However, evidences show that DNMT1 may also work together with DNMT3A and DNMT3B in de novo methyltransferase activity in certain genome in both embryonic cells and differentiated somatic cells $[19,20]$. Many interacting proteins have been reported to bind to their N-terminal region by biochemical interaction assay [14]. For example, DNMT1 directly interacts with histone modifying enzymes such as histone H3K9 methyltransferase SUV39H1, histone H3K27 methyltransferase EZH2, and histone deacytelase HDAC1 and HDAC2 [14,21]. DNMT1 also interacts with methyl-CpGbinding proteins such as MBD2, MBD3 and MeCP2 and with the heterochromatin binding protein HP1 [14].

Notably, DNMT1, DNMT3A, and DNMT3B are overexpressed in a coordinate manner in most tumor tissues and at a significantly higher level in cancer than in non-tumorous tissues [22-24]. The mechanism underlying DNMTs overexpression is worthy of comprehensive discussion. Delineating mechanisms of DNMTs overexpression will provide more information and strategies to remedy the altered epigenetic states. It will offer more exciting opportunities that can reactivate epigenetically silenced TSGs and critical anti-cancer pathways [25].

\section{Transcriptional regulation of DNMT gene expression}

The earlier study on transcriptional regulation of DNMT mediated by Ras-c-Jun signaling pathway provided a molecular explanation for the role of DNMT1 to carcinogenesis $[26,27]$. The expressions of DNMT1, DNMT3A and $D N M T 3 B$ genes are also controlled by $\mathrm{Sp} 1$ and $\mathrm{Sp} 3$ zinc finger proteins $[28,29]$. Wilms' tumour 1 protein has been shown to directly transactivate DNMT3A expression [30]. Homeobox B3 can bind to and activate DNMT3B gene [31]. In addition to transcription factors, several important transcriptional repressors have been reported to suppress the DNMT1, DNMT3A and DNMT3B gene expression, including p53, RB and FOXO3a (Table 1 and Figure 1). The major findings are described below.

\section{The p53-mediated regulation of DNMT genes}

The tumor suppressor gene $p 53$ encodes a transcription factor that mediates many downstream effects such as growth arrest and apoptosis through activation or repression of its target genes [46]. However, the $p 53$ gene is a frequent target of missense mutation rendering it unable to recognize the p53 consensus binding sites therefore loss of transcriptional function of p53 in cancers [47]. Sequencing analyses reveal that point mutation and small intragenic deletion/insertion of $p 53$ gene are significantly associated with DNMT1 protein overexpression [32]. A study shows that deletion of $p 53$ in the HCT116 human colon carcinoma cell line results in increase of DNMT1 mRNA and protein [48]. Wild-type p53 decreases DNMT1 promoter activity and expression level through the exon 1 region ( -19 to +317$)$ of DNMT1 promoter, which contains p53 putative binding sites, in lung cancer cells $[32,48]$. In addition, wild-type p53 protein has been shown to negatively regulate DNMT1 expression by forming a complex with Sp1 protein and chromatin modifiers on the DNMT1 promoter [32]. Low level of exogenous Sp1 expression enhances the repressive activity of endogenous p53 on the DNMT1 promoter, whereas a high level of Sp1 expression upregulates DNMT1 gene expression level in A549 (p53 wild-type) cells. In H1299 (p53 null) cells, exogenous Sp1 induces DNMT1 expression in a dosedependent manner. A high level of Sp1, via its $\mathrm{COOH}-$ terminal domain, induces interaction between p53 and MDM2, resulting in degradation of $\mathrm{p} 53$ by MDM2mediated ubiquitination [32]. Clinical data from 102 lung cancer patients indicated that overexpression of DNMT1 is significantly associated with $p 53$ mutation and high expression of Sp1 protein. In addition, patients with overexpression of both DNMT1 and Sp1 proteins show poor prognosis [32]. Cell and clinical data provide evidence that deregulation of DNMT1 is associated with gain of transcriptional activation of $\mathrm{Sp} 1$ and/or loss of repression of p53. DNMT1 overexpression is involved in epigenetic alterations of multiple TSGs that ultimately leads to lung tumorigenesis and poor prognosis [32].

Some reports have also shown that $\mathrm{Sp} 1$ and $\mathrm{Sp} 3$ increase the activity of DNMT1, DNMT3A, and DNMT3B promoters by physical binding to their promoters in mouse NIH3T3 cells or human embryonic kidney 293T cells $[28,29]$. p53 is shown to suppress the promoter activity and mRNA/protein expression of DNMT3A through binding to its promoter and the suppression can be attenuated by knockdown of p53 [33]. Whether overexpression of DNMT3A and DNMT3B resulted from the loss of transcriptional regulation of $\mathrm{p} 53 / \mathrm{Sp} 1$ warrants further investigation. It is justifiable to propose that overexpression of DNMTs is associated with the gain of transcriptional activation of $\mathrm{Sp} 1$ and/or the loss of repression of $\mathrm{p} 53$ (Figure 1A).

\section{The RB-mediated regulation of DNMT genes}

The RB (retinoblastoma) protein is a tumor suppressor, which plays a pivotal role in the negative control of the cell cycle and in tumor progression [49]. The RB protein represses gene transcription, required for transition from G1 to $\mathrm{S}$ phase, by directly binding to the transactivation domain of E2F and by binding to the promoter of the target genes as a complex with E2F [50]. RB also represses transcription by remodeling chromatin structure through interaction with proteins such as HP1, SWI/SNF, HDAC1 and SUV39H1, which are involved in DNA methylation, 
Table 1 Transcriptional regulation of DNMT promoter activity and/or mRNA expression

\begin{tabular}{|c|c|c|c|}
\hline Pathways & Mechanisms & DNMTs mRNA/promoters & References \\
\hline \multicolumn{4}{|l|}{ Down regulation } \\
\hline p53 & p53/Sp1 transcriptional repression & DNMT1/3A/3B & {$[32]$} \\
\hline $\mathrm{RB} / \mathrm{E} 2 \mathrm{~F}$ & RB/E2F transcriptional repression & DNMT1/3A & {$[33-36]$} \\
\hline FOXO3a & Transcriptional repression & DNMT3B & [37] \\
\hline \multicolumn{4}{|l|}{ Up regulation } \\
\hline Ras/AP-1 & AP1 transcriptional activation & DNMT1 & {$[26,27,38]$} \\
\hline Sp1 & Transcriptional activation & DNMT1/3A/3B & {$[28,29,32]$} \\
\hline Sp3 & Transcriptional activation & DNMT1/3A/3B & {$[28,29]$} \\
\hline E2F & Transcriptional activation & DNMT1 & {$[34,39]$} \\
\hline ERK & Unknow & DNMT1/3A & {$[40]$} \\
\hline $17 \beta$-estradiol & ER-dependent transcription activation & DNMT3B & [41] \\
\hline Homeobox B3 & Promoter binding & DNMT3B & [31] \\
\hline Wilms' tumour 1 & Transcriptional activation & DNMT3A & {$[30]$} \\
\hline \multicolumn{4}{|l|}{ Viruse induction } \\
\hline LMP1 & Activation of JNK/AP-1 pathway & DNMT1 & [42] \\
\hline BKV Tag and E1a & pRB/E2F pathway & DNMT1 & [43] \\
\hline $\mathrm{HBx}$ & Promoter transcriptional activator & DNMT1/3A & [44] \\
\hline $\mathrm{HBx}$ & Promoter transcriptional repression & DNMT3b & [44] \\
\hline HIV-1 & Through transcription factor AP-1 & DNMT1 & {$[45]$} \\
\hline
\end{tabular}

LMP1: latent membrane protein 1.

BKV Tag and E1a: Human polyomavirus BKV large T antigen and adenovirus E1a. $H B x$ : Hepatitis B virus X protein.

HIV-1: early expressed HIV-1 proteins.

nucleosome remodeling, histone deacetylation and histone methylation, respectively [51-54].

The mouse and human DNMT1 promoters are found to contain E2F binding sites that are required for RB/E2F regulation in wtPrE (wild-type prostate epithelial cell line) [34]. DNMT1 is negatively regulated by E2F-RB-HDAC pathway in mouse NIH3T3 embryonic fibroblast, monkey COS-7 kidney cell, and saos-2 human osteosarcoma cell lines [35]. In addition, DNMT1 mRNA can be diminished by overexpression of RB protein in saos- 2 cells and are induced by deletion of $R B$ gene in wtPrE cells [34,35]. $\mathrm{RB}$ also suppresses DNMT3A promoter activity and mRNA/protein expression through binding with E2F1 protein to the DNMT3A promoter [36]. Repression of DNMT3A by RB leads to the decrease of methylation level globally and TSG specifically, such as RARB, FHIT, and RASSF1A genes [36]. Together, these data suggest that $\mathrm{RB}$ is a transcriptional repressor of DNMT1 and DNMT3A genes (Figure 1B).

\section{The FOXO3a-mediated regulation of DNMT genes}

Forkhead $\mathrm{O}$ transcription factor $3 \mathrm{a}$ (FOXO3a) belongs to a large protein family of transcriptional regulators characterized by a conserved DNA-binding domain termed the "forkhead-box" [55]. To date, many reports indicate a tumor suppressor role for FOXO3a. For example, ectopic overexpression of FOXO3a significantly impairs tumor growth in cell and xenograft models in breast cancer and promotes apoptosis in leukemia and prostate cancer cells [56,57]. In addition, restrained transcriptional activity of FOXO3a in cancer cells results in promoting angiogenesis and tumor progression [58-60]. FOXO3a has been shown to transcriptionally up-regulate apoptotic-related gene such as p27kip [61], Bim [62], and Fas ligand [63]. In contrast, FOXO3a could transcriptionally repress microRNA21, which suppresses the expression of Fas ligand [64]. Of note, the gene deletion of $\mathrm{FOXO3a}$ is found in early-stage lung adenocarcinoma in smokers and tobacco carcinogen-initiated lung tumors in mice $[37,65]$. Restoration of FOXO3a in FOXO3a-deficient lung cancer cells increases the cell apoptosis response to nicotine-derived nitrosamino ketone-mediated DNA damage [66]. The last-mentioned two studies implicate that loss of FOXO3a may contribute to lung cancer pathogenesis.

We recently showed that FOXO3a negatively regulates $D N M T 3 B$ promoter activity by interacting with the binding element FOXO3a $(+166 \sim+173)$ of DNMT3B promoter [67]. Ectopically overexpressed FOXO3a or combined treatment with doxorubicin to induce FOXO3a nuclear accumulation leads to further binding at the distal $\mathrm{FOXO} 3 a$ 


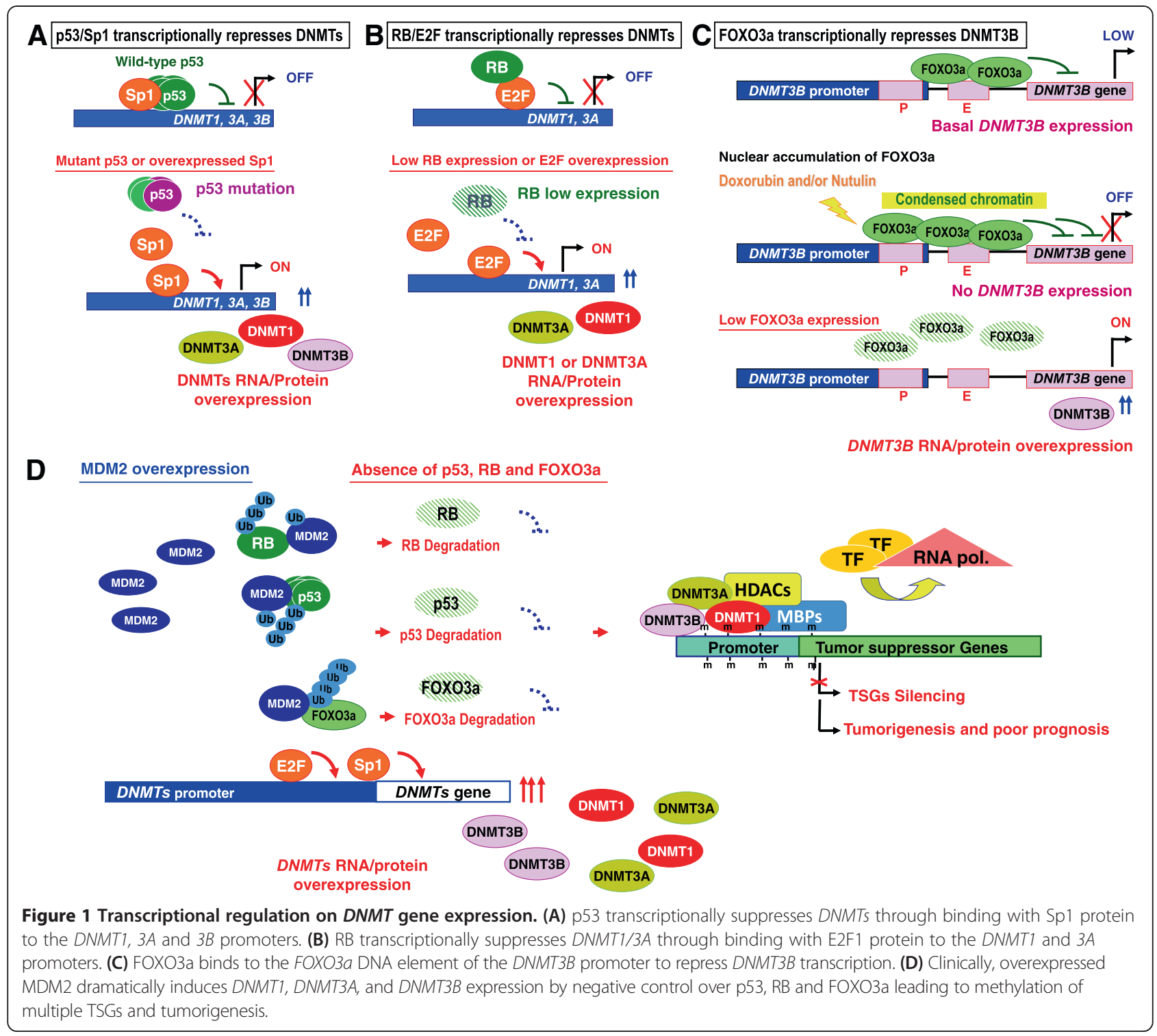

site $(-249 \sim-242)$. Abundant FOXO3a represses DNMT3B promoter by establishing a repressed chromatin structure, while knockdown of FOXO3a results in an open chromatin structure and high DNMT3B mRNA and protein expression. Importantly, enforced abundant nuclear accumulation of FOXO3a could decrease expression of DNMT3B with synergistic inhibition of tumor growth and decrease in methylation status on TSGs in human lung tumor xenograft specimens [67]. It is plausible that FOXO3a binds to the FOXO3a DNA element of the DNMT3B promoter to repress $D N M T 3 B$ expression (Figure $1 C$ ).

\section{Transcriptional deregulation of DNMT genes by MDM2 overexpression}

p53 protein is known to be degraded in cytoplasm by ubiquitin-mediated proteasomal degradation pathway modulated by MDM2 [68]. MDM2, an E3 ubiquitin ligase, also physically interacts with $\mathrm{RB}$ and FOXO3a resulting in degradation of RB and FOXO3a proteins $[69,70]$. Overexpression of MDM2 has been demonstrated in many human cancers [36,71]. In addition, oncogenic ERK phosphorylates FOXO3a at $\mathrm{Ser}^{294}, \mathrm{Ser}^{344}$, and $\mathrm{Ser}^{425}$ thereby enhancing the interaction with MDM2 and results in promoting degradation of FOXO3a [69]. Therefore, we hypothesized that MDM2 plays a critical role in regulating the DNMT genes by synergistically destabilizing p53, RB and FOXO3a proteins. To test this hypothesis we analyzed the relationship of MDM2 protein with $\mathrm{p} 53, \mathrm{RB}, \mathrm{FOXO} 3 \mathrm{a}$ and DNMT proteins in lung cancer cell, xenograft and patient models. Dramatic induction of DNMT3A and DNMT3B expression by ectopic overexpression MDM2 suggests a negative 
control of MDM2 over RB and FOXO3a [36,67]. Note that treatment with the MDM2 inhibitor, Nutlin-3, significantly reduces DNMT3A and DNMT3B expression and methylation of TSGs, as well as tumor growth in vivo $[36,67]$. Clinically, MDM2 overexpression inversely correlates with expression of $\mathrm{p} 53, \mathrm{RB}$ and FOXO3a proteins in tumor tissues from lung cancer patients. Importantly, a sub-group of patient with gene expression signature of DNMTs high, p53/RB/FOXO3a low, and MDM2 high expression profile correlating with poor survival [33,36,67]. This defined signature may serve as a prognostic marker in lung cancer patients whose genomic DNA may exert promoter hypermethylation in multiple TSGs (Figure 1D).

\section{The microRNA-mediated regulation of DNMTs}

MicroRNAs (miRs) are small, noncoding RNAs that regulate expression of many genes. Recent studies suggest that abnormal expressions of miRs are involved in pathogenesis of different types of human cancers [72]. Previous reports have shown that expression profiles of miRs in lung cancer are different from normal lung. The miR-29 family (29a, 29b, and 29c) has intriguing complementarities to the 3 '-UTRs of DNM3A and $D N M T 3 B$ [73]. The expression of miR-29s is inversely correlated to DNMT3A and DNMT3B in lung cancer tissues, and miR-29s directly target the 3'-UTRs of both DNMT3A and DNMT3B. The enforced expression of miR-29s in lung cancer cell lines restores normal patterns of DNA methylation. The miR-29s further induces re-expression of methylation-silenced TSGs, such as FHIT and $W W O X$, and inhibits tumorigenicity in vitro and in vivo [73]. Enforced miR-29b expression in acute myeloid leukemia cells also results in marked reduction in the expression of DNMT1, DNMT3A, and DNMT3B and ultimately to re-expression of $p 15^{I N K 4 b}$ and ESR1 via promoter DNA hypomethylation [74]. Of note, an inverse correlation between miR-29c expression and DNMT3A and DNMT3B protein expression has been reported in melanomas [75].

In addition to miR-29s, ectopic expression of miRNA$148 \mathrm{a}$ in lung cancer cell lines also results in a significant reduction in the expression of DNMT1 [76]. Using luciferase reporter assay, DNMT1 mRNA was found to be a target of miR-148b and miR-152 [77]. Antagomir-mediated knock-down and re-expression of miRs assays support that miR-148b, miR-29c, and miR-26b down-regulate DNMT3B gene in breast cancer cells [78]. Furthermore, overexpression of miR-148b and -152 in pancreatic cancer cell lines decreases DNMT1 expression, restores normal DNA methylation patterns and induces re-expression of TSGs, like BNIP3 and SPARC [77]. It is to be noted that miR-143 was reported to directly target DNMT3A. In colorectal cancer tissues, the miR-143 expression was observed to be inversely correlated with DNMT3A mRNA and protein expression [79]. Specifically, miR-1741, miR-16c, miR-222 and miR-1632 are found to influence expression of DNMT3A or DNMT3B, possibly through their 3 '-UTR post-transcriptional regulation [80]. Table 2 summarizes the regulation of DNMTs by miRs.

\section{Post-translational modification of DNMT proteins}

Several important post-translational modification including acetylation and phosphorylation have been reported to mediate protein stability and activity of the DNMTs especially DNMT1 (Figures 2 and 3). The major findings are described below.

\section{Acetylation-mediated DNMT stability and activity}

DNMT1 has been shown to be destabilized by acetylationmediated ubiquitination. DNMT1 physically interacts with acetyltransferase Tip60, herpesvirus-associated ubiquitin specific protease (HAUSP), ubiquitin-like containing PHD and RING finger domains 1 (UHRF1), HDAC1 and PCNA on chromatin [81]. Tip60 promotes acetylation of DNMT1, which triggers ubiquitination by the E3 ligase UHRF1, thereby targeting DNMT1 for proteasomal degradation during late $\mathrm{S}$ phase [82]. Conversely, HAUSP and HDAC1 protect DNMT1 from degradation through deubiquitination and deacetylation, respectively [81] (Figure 2A). In addition, the pleiotropic regulator of $G$ protein signaling (RGS) family member RGS6 facilitates Tip60-mediated degradation of DNMT1 [83]. RGS6 may serve as a scaffold of Tip60, DNMT1 and Dnmt1associated protein (DMAP1) to facilitate Tip60 acetylation of DNMT1 and subsequent DNMT1 polyubiquitylation and degradation [83] (Figure 2B). In contrast, the histone deacetylase SIRT1 physically associates with DNMT1 and deacetylates acetylated DNMT1 in vitro and in vivo [84]. Using mass spectrometry analysis, 12 new acetylated lysine sites are identified in DNMT1 [85]. Deacetylation of different lysines on DNMT1 by SIRT1 has different effects on the functions of DNMT1. For example, deacetylation of Lys1349 and Lys1415 by SIRT1 in the catalytic domain of DNMT1 enhances the methyltransferase activity of DNMT1 (Figure 2C). Collectively, these findings suggest that deacetylation of the identified acetylated lysine sites in DNMT1 may be involved in the impaired activity of DNMT1.

\section{Phosphorylation-mediated DNMT stability and activity}

Lin et al. found that the tobacco-specific nitrosamine 4-(methylnitrosamino)-1-(3-pyridyl)-1-butanone (NNK) increases DNMT1 protein expression and activity [86]. Strong nuclear staining of DNMT1 protein in lung tumor tissues is significantly associated with smoking status of lung cancer patients $[22,86]$. Cigarette smoking is a dominant risk factor for lung cancer. Among the multiple components of tobacco smoke, 20 carcinogens 
Table 2 Regulation of DNMT expression by miRNAs

\begin{tabular}{|c|c|c|c|c|}
\hline Pathway & Regulated regions & DNMTs & Cancer types & References \\
\hline miR-16c & 3'-UTRs & DNMT3B & in vitro & {$[80]$} \\
\hline miR-26b & ND & DNMT3B & breast cancer & [78] \\
\hline miR-29a & 3'-UTRs & DNMT3A/3B & lung cancer & [73] \\
\hline miR-29b & 3'-UTRs & DNMT1/3A/3B & lung, ALL and melanomas & {$[73,74]$} \\
\hline $\operatorname{miR}-29 c$ & 3'-UTRs & DNMT3A/3B & breast, lung and melanomas & {$[73,75,78]$} \\
\hline miR-143 & 3'-UTRs & DNMT3A & colorectal & [79] \\
\hline miR-148a & ND & DNMT1 & lung and pancreas & {$[76,77]$} \\
\hline miR-148b & ND & DNMT3B & breast cancer & [78] \\
\hline miR-152 & ND & DNMT1 & pancreas & [77] \\
\hline miR-222 & 3'-UTRs & DNMT3B & in vitro & {$[80]$} \\
\hline miR-1632 & 3'-UTRs & DNMT3B & in vitro & [80] \\
\hline miR-1741 & 3'-UTRs & DNMT3A & in vitro & [80] \\
\hline
\end{tabular}

ND: non-determined.

ALL: Acute lymphoblastic leukemia.

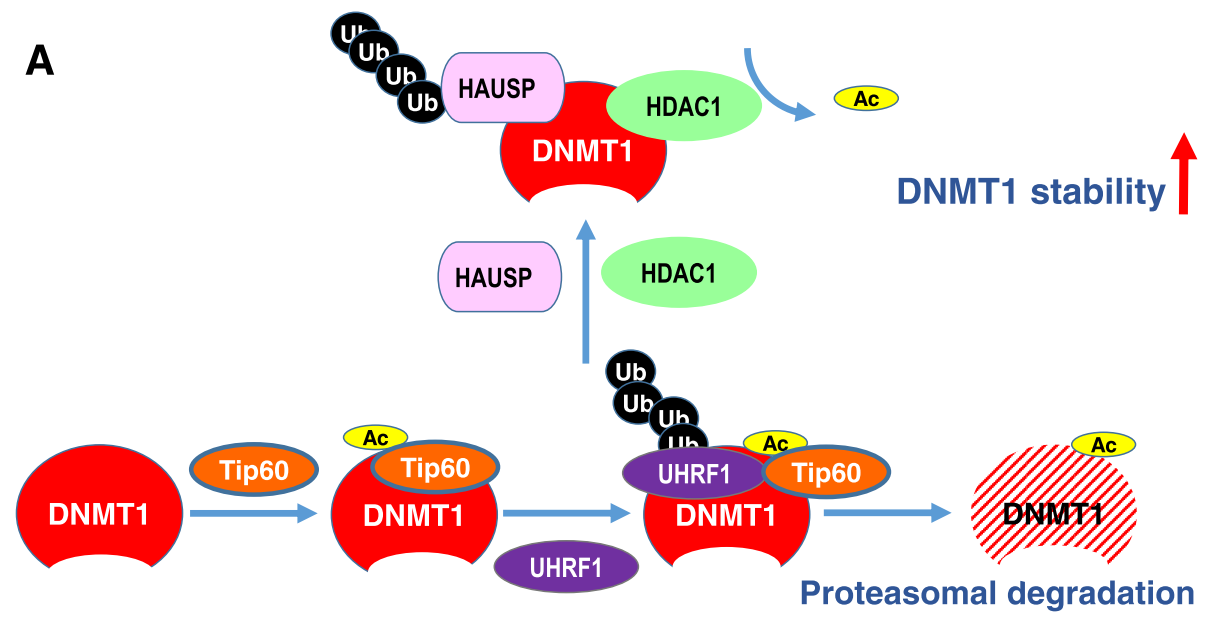

B
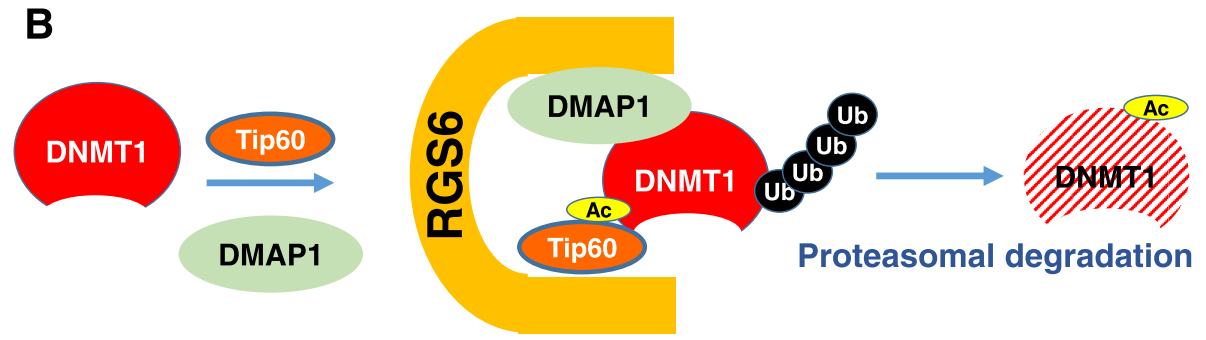

C
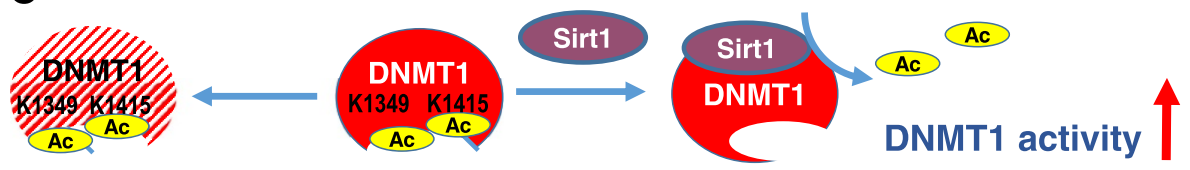

Figure 2 Acetylation-mediated DNMT stability and activity. (A) Tip60 promotes acetylation of DNMT1, which triggers ubiquitination by the E3 ligase UHRF1, thereby targeting DNMT1 for proteasomal degradation. (B) RGS6 serves as a scaffold to facilitate Tip60 acetylation of DNMT1 and subsequent DNMT1 degradation. (C) Deacetylation of Lys1349 and Lys1415 by SIRT1 in the catalytic domain of DNMT1 enhances the methyltransferase activity of DNMT1. 


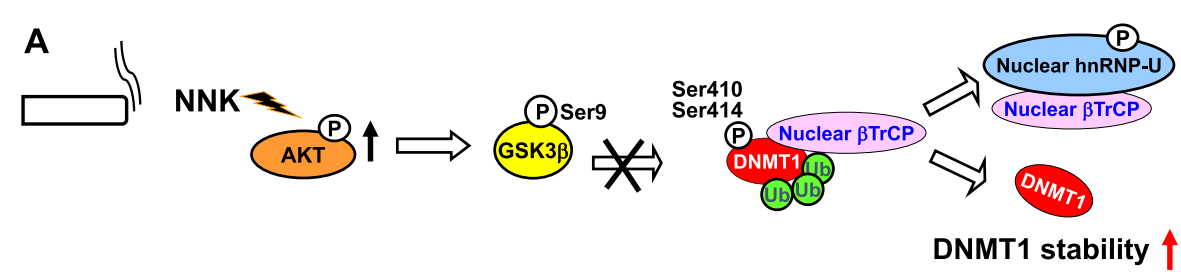

$\mathbf{B}$
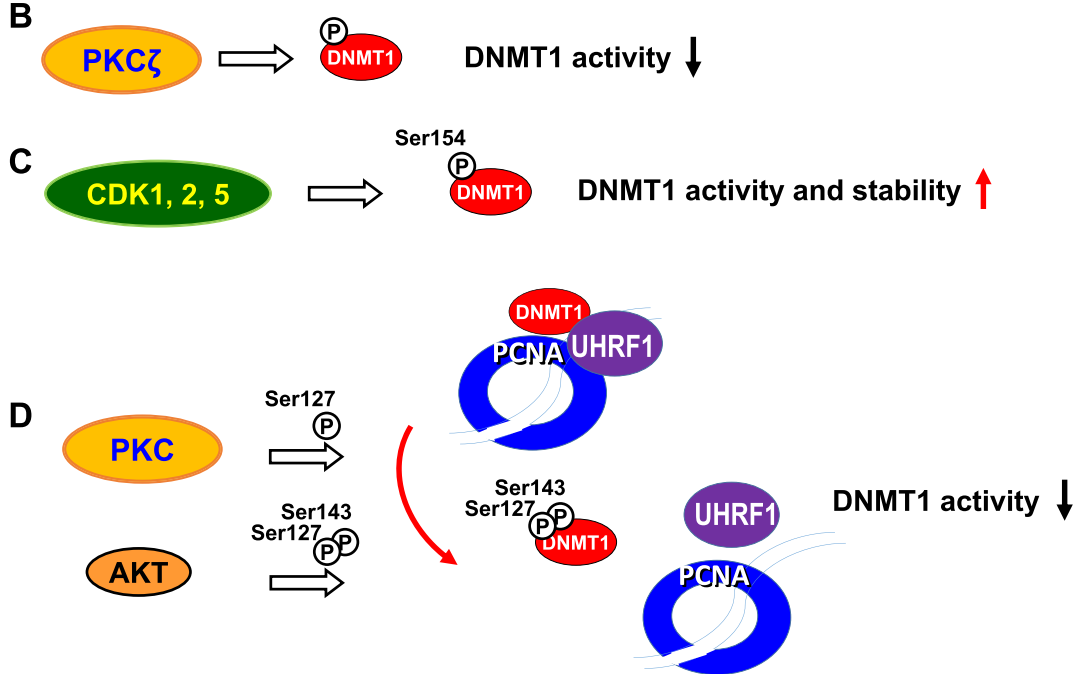

Figure 3 Phosphorylation-mediated DNMT stability and activity. (A) Cigarette carcinogen NNK activates AKT, inhibits GSK3ß-mediated DNMT1 phosphorylation at Ser410 and Ser414, thereby leading to DNMT1 protein accumulation. (B) Phosphorylation of DNMT1 by PKCZ reduces its methyltransferase activity. (C) Phosphorylation of DNMT1 at Ser154 by CDK1, 2 and 5 enhances enzymatic activity and protein stability of DNMT1. (D) Phosphorylation of DNMT1 at Ser127 and/or Ser143 decreases its interaction with UHRF1 ubiquitin-like protein and renders DNMT1 less efficient to catalyze the DNA methyltransferase activity at the replication fork.

convincingly cause lung tumors in laboratory animals or humans. Of these, NNK is likely to play a major role because NNK has been shown to induce lung tumor in rats, mice and hamsters [87]. In addition, exposure of NNK not only causes gene mutation, but also stimulates the promoter hypermethylation on multiple TSGs in bladder, liver, and lung cancers, including FHIT, $R A S S F 1 A$, and $p 16^{I N K 4 A}, D A P K 1, R U N X 3, R A R \beta$ and SFRP genes [88-93]. Notably, NNK stimulates the AKT, NF-kB, EGFR, and ERK1/2 signal pathways resulting in increased cell proliferation and survival [94-96]. It has previously been shown that AKT inactivates GSK3 $\beta$ Ser/Thr kinase, which phosphorylates its substrate protein and recruits the E3-ubiqutin ligase $\beta \mathrm{TrCP}$, leading to substrate degradation $[97,98]$. In addition, stabilization of DNMT1 protein is regulated by inhibiting GSK3 $\beta$ mediated phosphorylation and proteasomal degradation of DNMT1 upon activation of $\mathrm{T}$ cell receptor signaling [99]. Lin et al. showed that GSK3 $\beta$ interacts with DNMT1 to phosphorylate DNMT1 at Ser410 and Ser414 and promotes binding of DNMT1 by $\beta \mathrm{TrCP}$ leading to proteasomal degradation of DNMT1. They also demonstrated that DNMT1 contains a domain, ESGXXS, similar to the conserved binding motif DSGXXS of $\beta \operatorname{TrCP}$ [86].
This study suggests that NNK activates AKT, then inhibits GSK3 $\beta / \beta \operatorname{TrCP}-$ mediated protein degradation, leading to DNMT1 protein accumulation [86]. In addition, DNMT1/ $\beta \mathrm{TrCP}$ interaction could be interrupted by treating cells with NNK. NNK also induces $\beta$ TrCP translocation to the cytoplasm by interacting with phosphorylated heterogeneous nuclear ribonucleoprotein U (hnRNP-U) shuttling protein mediated by AKT. Therefore, NNK exposure results in DNMT1 nuclear accumulation and hypermethylation of the promoters of multiple TSGs [86]. Figure 3A shows the phosphorylation-mediated DNMT stability control induced by the cigarette carcinogen NNK.

In addition to Ser410 and Ser414 of DNMT1, recent studies have suggested that the enzymatic activity of DNMT1 is possibly modulated by phosphorylation of Ser/Thr residues located in the $\mathrm{N}$-terminal domain of the enzyme [100-102]. Protein kinase C (PKC) $\alpha, \beta I$, $\beta I I, \delta, \gamma, \eta, \zeta$ and $\mu$ preferentially phosphorylate the Nterminal domain of human DNMT1 [102]. Phosphoryl-

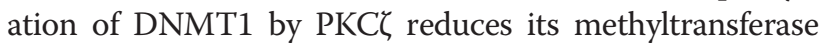
activity in vitro [102] (Figure 3B). In addition, phosphorylation of DNMT1 at Ser154 by CDKs, including CDK1, 2 and 5, is important to enhance enzymatic activity and protein stability of DNMT1 [100] (Figure 3C). AKT and PKC 
are capable of phosphorylating DNMT1 at the residues Ser127/143 and Ser127, respectively [101]. Phosphorylation of the DNMT1 at Ser127 and/or Ser143 decreases the capacity of the protein to interact with PCNA and UHRF1 proteins and renders DNMT1 less efficient to catalyze methylation [101] (Figure 3D). Interestingly, phosphorylation of DNMT1 at Ser143 by AKT1 interferes with the methylation of Lys142 by SET7, a known histone methyltransferase involved in proteasome-mediated degradation of DNMT1 [103].

\section{The impact of viruses on the regulation of DNMT genes}

Several viruses have been reported to increase DNMTs expression (Table 1). Epstein-Barr virus (EBV) is closely associated with human malignancies, including nasopharyngeal carcinoma, Burkitt's lymphoma, T-cell lymphoma, gastric carcinoma [104,105]. Epigenetic regulation of EBV plays a central role in viral latency and viral-associated carcinogenesis [105]. EBV latent membrane protein 1 (LMP1) activates cellular DNMTs, resulting in hypermethylation and silencing of E-cadherin. LMP1-mediated DNMT1 activation involves JNK but not NF- $\mathrm{B}$ and p38 mitogen-activated protein kinases [42]. The EBV oncogene product LMP1, induces promoter hypermethylation of $R A R \beta 2$ via up-regulation of DNMT1, DNMT3A, and DNMT3B proteins, leading to decrease in RAR $\beta 2$ expression in nasopharyngeal carcinoma cell lines [43]. Human polyomavirus BKV large $\mathrm{T}$ antigen and adenovirus E1a also strongly increase DNMT1 expression. Mutation of the E2F sites within the DNMT1 promoter dramatically abrogates transcriptional activation, suggesting that BKV viral induction of DNMT1 may be through modulation of pRB/E2F pathway [39].

The hepatitis $B$ virus ( $\mathrm{HBV}$ ) $\mathrm{X}$ protein $(\mathrm{HBx})$ plays a key role in the molecular pathogenesis of HBV-related hepatocellular carcinoma. HBx expression increases total DNMT activities and selectively promotes regional hypermethylation of specific TSGs, including RASSF1A, GSTP1, and $C D K N 2 B$, in $\mathrm{pHBx}$-transfected cells [44]. Another study shows that enforced $\mathrm{HBx}$ suppresses RASSF1A possibly via induction of DNMT1 and DNMT3B expression [106].

Human immunodeficiency virus type 1 (HIV-1) also has been reported to induce DNMT1 through the responsive element residing in the -1634 to +71 of DNMT1 promoter [45]. The increase in expression of DNMT1 and overall genomic methylation as well as hypermethylation of the $p 16^{I N K 4 A}$ gene are found when infected with HIV-1 in Hut 78 lymphoid cells [107]. HIV infection of human regulatory $\mathrm{T}$ cells down-regulates FOXP3 expression mediated by increasing DNMT3B levels and DNA methylation in the FOXP3 gene [108]. Therefore, the ability of increased DNMT activity to downregulate the expression of critical genes may be one of the mechanisms for dysfunction of T cells in HIV-1-infected individuals.

\section{Concluding remark}

DNMTs are the enzymes which catalyze the CpG DNA methylation and have been reported to be over-expressed in various cancers. The mechanisms of DNMT overexpression are worthy of investigation. The transcriptional up-regulation on DNMT gene expression can be induced by Ras-c-Jun signaling pathway, Sp1 and Sp3 zinc finger proteins, wilms' tumour 1, homeobox B3 and various human viruses. Loss of transcriptional repression control on DNMT genes has also been reported. For example, p53 transcriptionally suppresses DNMTs through binding with Sp1 protein to the $D N M T$ promoters. RB transcriptionally suppresses $D N M T 1 / 3 A$ through binding with E2F1 protein to the DNMT1 and $3 A$ promoters. FOXO3a binds to the FOXO3a DNA element of the DNMT3B promoter to repress $D N M T 3 B$ transcription. In addition, overexpressed MDM2 may induce DNMT1, DNMT3A, and DNMT3B expression by negative control over $\mathrm{p} 53, \mathrm{RB}$ and FOXO3a. Low expressions of some miRs such as miR-29s, miR-143, miR-148a and miR-152 are associated with DNMT overexpression in various cancers. Several important post-translational modification including acetylation and phosphorylation have been reported to affect protein stability and activity of the DNMTs especially DNMT1. Therefore, drugs targeting DNMT protein inactivation and depletion, such as MDM2, AKT and CDKs inhibitors may prove to be a good therapeutic strategy for cancer treatment. Combined treatment with the known DNMT inhibitors such as decitabine could be a potential therapeutic strategy through epigenetic modulation warranting further investigation in cancer treatment.

\section{Abbreviations}

DNMT: DNA methyltransferase; FOXO3a: forkhead O transcription factor 3a; $\mathrm{HBx}$ : hepatitis B virus X protein; HAUSP: herpesvirus-associated ubiquitin specific protease; hnRNP-U: heterogeneous nuclear ribonucleoprotein $U_{\text {; }}$ LMP1: latent membrane protein 1; miR: microRNA; NNK: nitrosamine 4-(methylnitrosamino)-1-(3-pyridyl)-1-butanone; RB: retinoblastoma; RGS: regulator of G protein signaling; TSG: tumor suppressor gene; UHRF1: ubiquitin-like containing PHD and RING finger domains 1.

\section{Competing interests}

The authors declare that they have no competing interests.

\section{Authors' contributions}

RKL and YCW wrote the review. Both authors read and approved the final manuscript.

\section{Acknowledgements}

This work was supported by Taiwan National Science Council grant 100-2320-B-038-002 to RKL; and Taiwan National Science Council grant 102-2627-B-006-010 and Taiwan Ministry of Health and Welfare grant 103-TDU-PB-211-133005 to YCW. 


\section{Author details}

'Graduate Institute of Pharmacognosy, Taipei Medical University, 250 Wu-Hsing Street, Taipei 110, Taiwan. ${ }^{2}$ Department of Pharmacology and Institute of Basic Medical Sciences, National Cheng Kung University, No.1, University Road, Tainan 70101, Taiwan. ${ }^{3}$ Program for the Clinical Drug Discovery from Botanical Herbs, Taipei Medical University, 250 Wu-Hsing Street, Taipei 110, Taiwan. ${ }^{4}$ Program for Clinical Pharmacogenomics and Pharmacoproteomics, Taipei Medical University, 250 Wu-Hsing Street, Taipei 110, Taiwan

Received: 21 May 2014 Accepted: 1 July 2014

Published: 19 August 2014

\section{References}

1. International Agency for Research on Cancer: GLOBOCAN 2012: Estimated Cancer Incidence, Mortality and Prevalence Worldwide in 2012. 2013.

2. Taby R, Issa JP: Cancer epigenetics. CA Cancer J Clin 2010, 60:376-392.

3. Belinsky SA: Gene-promoter hypermethylation as a biomarker in lung cancer. Nat Rev Cancer 2004, 4:707-717.

4. Momparler RL: Cancer epigenetics. Oncogene 2003, 22:6479-6483.

5. Lee EJ, Luo J, Wilson JM, Shi H: Analyzing the cancer methylome through targeted bisulfite sequencing. Cancer Lett 2013, 340:171-178.

6. Ma X, Wang YW, Zhang MQ, Gazdar AF: DNA methylation data analysis and its application to cancer research. Epigenomics 2013, 5:301-316.

7. Costello JF, Fruhwald MC, Smiraglia DJ, Rush L, Robertson GP, Gao X, Wright FA, Feramisco JD, Peltomaki $P$, Lang JC, Schuller DE, Yu L, Bloomfield CD, Caligiuri MA, Yates A, Nishikawa R, Su Huang H, Petrelli NJ, Zhang X, O'Dorisio MS, Held WA, Cavenee WK, Plass C: Aberrant CpG-island methylation has non-random and tumour-type-specific patterns. Nat Genet 2000, 24:132-138.

8. Hansen KD, Timp W, Bravo HC, Sabunciyan S, Langmead B, McDonald OG, Wen B, Wu H, Liu Y, Diep D, Briem E, Zhang K, lrizarry RA, Feinberg AP. Increased methylation variation in epigenetic domains across cancer types. Nat Genet 2011, 43:768-775.

9. Jamaluddin MS, Yang X, Wang H: Hyperhomocysteinemia, DNA methylation and vascular disease. Clin Chem Lab Med 2007, 45:1660-1666.

10. Costa E, Dong E, Grayson DR, Guidotti A, Ruzicka W, Veldic M: Reviewing the role of DNA (cytosine-5) methyltransferase overexpression in the cortical GABAergic dysfunction associated with psychosis vulnerability. Epigenetics 2007, 2:29-36.

11. Kanai $Y$ : Alterations of DNA methylation and clinicopathological diversity of human cancers. Pathol Int 2008, 58:544-558.

12. Egger G, Liang G, Aparicio A, Jones PA: Epigenetics in human disease and prospects for epigenetic therapy. Nature 2004, 429:457-463.

13. Rhee I, Bachman KE, Park BH, Jair KW, Yen RW, Schuebel KE, Cui H, Feinberg AP, Lengauer C, Kinzler KW, Baylin SB, Vogelstein B: DNMT1 and DNMT3b cooperate to silence genes in human cancer cells. Nature 2002, 416:552-556.

14. Hermann A, Gowher $H$, Jeltsch A: Biochemistry and biology of mammalian DNA methyltransferases. Cell Mol Life Sci 2004, 61:2571-2587.

15. Pradhan S, Talbot D, Sha M, Benner J, Hornstra L, Li E, Jaenisch R, Roberts $\mathrm{RJ}$ : Baculovirus-mediated expression and characterization of the full-length murine DNA methyltransferase. Nucleic Acids Res 1997, 25:4666-4673.

16. Fatemi M, Hermann A, Pradhan S, Jeltsch A: The activity of the murine DNA methyltransferase Dnmt1 is controlled by interaction of the catalytic domain with the $\mathrm{N}$-terminal part of the enzyme leading to an allosteric activation of the enzyme after binding to methylated DNA. J Mol Biol 2001, 309:1189-1199.

17. Goyal R, Reinhardt R, Jeltsch A: Accuracy of DNA methylation pattern preservation by the Dnmt1 methyltransferase. Nucleic Acids Res 2006 34:1182-1188.

18. Chuang LS, lan HI, Koh TW, Ng HH, Xu G, Li BF: Human DNA-(cytosine-5) methyltransferase-PCNA complex as a target for p21WAF1. Science 1997 277:1996-2000.

19. Ko YG, Nishino K, Hattori N, Arai Y, Tanaka S, Shiota K: Stage-by-stage change in DNA methylation status of Dnmt1 locus during mouse early development. J Biol Chem 2005, 280:9627-9634.

20. Ratnam S, Mertineit C, Ding F, Howell CY, Clarke HJ, Bestor TH, Chaillet JR, Trasler JM: Dynamics of Dnmt1 methyltransferase expression and intracellular localization during oogenesis and preimplantation development. Dev Biol 2002, 245:304-314.
21. Hernandez-Munoz I, Taghavi P, Kuijl C, Neefjes J, van Lohuizen M: Association of BMI1 with polycomb bodies is dynamic and requires $\mathrm{PRC2} / \mathrm{EZH} 2$ and the maintenance DNA methyltransferase DNMT1. Mol Cell Biol 2005, 25:11047-11058.

22. Lin RK, Hsu HS, Chang JW, Chen CY, Chen JT, Wang YC: Alteration of DNA methyltransferases contributes to $5^{\prime} \mathrm{CpG}$ methylation and poor prognosis in lung cancer. Lung Cancer 2007, 55:205-213.

23. Mizuno S, Chijiwa T, Okamura T, Akashi K, Fukumaki Y, Niho Y, Sasaki H: Expression of DNA methyltransferases DNMT1, 3A, and 3B in normal hematopoiesis and in acute and chronic myelogenous leukemia. Blood 2001, 97:1172-1179

24. Qu Y, Mu G, Wu Y, Dai X, Zhou F, Xu X, Wang Y, Wei F: Overexpression of DNA methyltransferases $1,3 a$, and $3 b$ significantly correlates with retinoblastoma tumorigenesis. Am J Clin Pathol 2010, 134:826-834.

25. Esteller M: DNA methylation and cancer therapy: new developments and expectations. Curr Opin Oncol 2005, 17:55-60.

26. Bakin AV, Curran T: Role of DNA 5-methylcytosine transferase in cell transformation by fos. Science 1999, 283:387-390.

27. Bigey P, Ramchandani S, Theberge J, Araujo FD, Szyf M: Transcriptional regulation of the human DNA Methyltransferase $(\mathrm{dnmt} 1)$ gene. Gene 2000, 242:407-418.

28. Jinawath A, Miyake S, Yanagisawa Y, Akiyama Y, Yuasa Y: Transcriptional regulation of the human DNA methyltransferase $3 \mathrm{~A}$ and $3 \mathrm{~B}$ genes by Sp3 and Sp1 zinc finger proteins. Biochem J 2005, 385:557-564.

29. Kishikawa S, Murata T, Kimura H, Shiota K, Yokoyama KK: Regulation of transcription of the Dnmt1 gene by Sp1 and Sp3 zinc finger proteins. Eur J Biochem 2002, 269:2961-2970.

30. Szemes M, Dallosso AR, Melegh Z, Curry T, Li Y, Rivers C, Uney J, Magdefrau AS, Schwiderski K, Park JH, Brown KW, Shandilya J, Roberts SG, Malik K: Control of epigenetic states by WT1 via regulation of de novo DNA methyltransferase 3A. Human Mol Genet 2013, 22:74-83.

31. Palakurthy RK, Wajapeyee N, Santra MK, Gazin C, Lin L, Gobeil S, Green MR: Epigenetic silencing of the RASSF1A tumor suppressor gene through HOXB3-mediated induction of DNMT3B expression. Mol Cell 2009, 36:219-230

32. Lin RK, Wu CY, Chang JW, Juan $\sqcup$, Hsu HS, Chen CY, Lu YY, Tang YA, Yang YC, Yang PC, Wang YC: Dysregulation of p53/Sp1 control leads to DNA methyltransferase-1 overexpression in lung cancer. Cancer Res 2010, 70:5807-5817.

33. Tang YA, Tsai YT, Lin RK, Hsu HS, Chen CY, Wang YC: Deregulation of p53 and RB Transcriptional Control of DNA Methyltransferases in Lung Cancer. J Cancer Res Pract 2014, 30:88-101.

34. McCabe MT, Davis JN, Day ML: Regulation of DNA methyltransferase 1 by the pRb/E2F1 pathway. Cancer Res 2005, 65:3624-3632.

35. Kimura H, Nakamura T, Ogawa T, Tanaka S, Shiota K: Transcription of mouse DNA methyltransferase 1 (Dnmt1) is regulated by both E2F-Rb-HDAC-dependent and -independent pathways. Nucleic Acids Res 2003, 31:3101-3113

36. Tang YA, Lin RK, Tsai YT, Hsu HS, Yang YC, Chen CY, Wang YC: MDM2 overexpression deregulates the transcriptional control of RB/E2F leading to DNA methyltransferase $3 \mathrm{~A}$ overexpression in lung cancer. Clin Cancer Res 2012, 18:4325-4333.

37. Herzog CR, Blake DC Jr, Mikse OR, Grigoryeva LS, Gundermann EL: FoxO3a gene is a target of deletion in mouse lung adenocarcinoma. Oncol Rep 2009, 22:837-843.

38. Rouleau J, MacLeod AR, Szyf M: Regulation of the DNA methyltransferase by the Ras-AP-1 signaling pathway. J Biol Chem 1995, 270:1595-1601.

39. McCabe MT, Low JA, Imperiale MJ, Day ML: Human polyomavirus BKV transcriptionally activates DNA methyltransferase 1 through the $\mathrm{pRb} / \mathrm{E} 2 \mathrm{~F}$ pathway. Oncogene 2006, 25:2727-2735.

40. Deng C, Lu Q, Zhang Z, Rao T, Attwood J, Yung R, Richardson B: Hydralazine may induce autoimmunity by inhibiting extracellular signal-regulated kinase pathway signaling. Arthritis Rheum 2003, 48:746-756.

41. Cui M, Wen Z, Yang Z, Chen J, Wang F: Estrogen regulates DNA methyltransferase 3B expression in Ishikawa endometrial adenocarcinoma cells. Mol Biol Rep 2009, 36:2201-2207.

42. Tsai CL, Li HP, Lu YJ, Hsueh C, Liang Y, Chen CL, Tsao SW, Tse KP, Yu JS, Chang YS: Activation of DNA methyltransferase 1 by EBV LMP1 Involves c-Jun NH(2)-terminal kinase signaling. Cancer Res 2006, 66:11668-11676. 
43. Seo SY, Kim EO, Jang KL: Epstein-Barr virus latent membrane protein 1 suppresses the growth-inhibitory effect of retinoic acid by inhibiting retinoic acid receptor-beta2 expression via DNA methylation. Cancer Lett 2008, 270:66-76.

44. Park IY, Sohn BH, Yu E, Suh DJ, Chung YH, Lee JH, Surzycki SJ, Lee YI: Aberrant epigenetic modifications in hepatocarcinogenesis induced by hepatitis B virus X protein. Gastroenterology 2007, 132:1476-1494.

45. Youngblood B, Reich NO: The early expressed HIV-1 genes regulate DNMT1 expression. Epigenetics 2008, 3:149-156.

46. Selivanova G: Wild type $\mathrm{p} 53$ reactivation: From lab bench to clinic. FEBS Lett 2014, 588:2628-2638

47. Sigal A, Rotter $\mathrm{V}$ : Oncogenic mutations of the $\mathrm{p} 53$ tumor suppressor: the demons of the guardian of the genome. Cancer Res 2000, 60:6788-6793.

48. Peterson EJ, Bogler O, Taylor SM: p53-mediated repression of DNA methyltransferase 1 expression by specific DNA binding. Cancer Res 2003, 63:6579-6582.

49. Giacinti C, Giordano A: RB and cell cycle progression. Oncogene 2006, 25:5220-5227

50. Dyson N: The regulation of E2F by pRB-family proteins. Genes Dev 1998, 12:2245-2262.

51. Siddiqui H, Fox SR, Gunawardena RW, Knudsen ES: Loss of RB compromises specific heterochromatin modifications and modulates HP1alpha dynamics. J Cell Physiol 2007, 211:131-137.

52. Fuks F, Burgers WA, Godin N, Kasai M, Kouzarides T: Dnmt3a binds deacetylases and is recruited by a sequence-specific repressor to silence transcription. Embo J 2001, 20:2536-2544.

53. Zhang HS, Dean DC: Rb-mediated chromatin structure regulation and transcriptional repression. Oncogene 2001, 20:3134-3138.

54. Nielsen SJ, Schneider R, Bauer UM, Bannister AJ, Morrison A, O'Carroll D, Firestein R, Cleary M, Jenuwein T, Herrera RE, Kouzarides T: Rb targets histone $\mathrm{H} 3$ methylation and HP1 to promoters. Nature 2001, 412:561-565.

55. Tsai KL, Sun YJ, Huang CY, Yang JY, Hung MC, Hsiao CD: Crystal structure of the human FOXO3a-DBD/DNA complex suggests the effects of post-translational modification. Nucleic Acids Res 2007, 35:6984-6994.

56. Medema RH, Kops GJ, Bos JL, Burgering BM: AFX-like Forkhead transcription factors mediate cell-cycle regulation by Ras and PKB through p27kip1. Nature 2000, 404:782-787.

57. Modur V, Nagarajan R, Evers BM, Milbrandt J: FOXO proteins regulate tumor necrosis factor-related apoptosis inducing ligand expression. Implications for PTEN mutation in prostate cancer. J Biol Chem 2002, 277:47928-47937.

58. Arden KC: Multiple roles of FOXO transcription factors in mammalian cells point to multiple roles in cancer. Exp Gerontol 2006, 41:709-717.

59. Greer EL, Brunet A: FOXO transcription factors at the interface between longevity and tumor suppression. Oncogene 2005, 24:7410-7425.

60. Potente M, Urbich C, Sasaki K, Hofmann WK, Heeschen C, Aicher A, Kollipara R, DePinho RA, Zeiher AM, Dimmeler S: Involvement of Foxo transcription factors in angiogenesis and postnatal neovascularization. J Clin Invest 2005, 115:2382-2392.

61. Dijkers PF, Medema RH, Pals C, Banerji L, Thomas NS, Lam EW, Burgering BM, Raaijmakers JA, Lammers JW, Koenderman L, Coffer PJ: Forkhead transcription factor FKHR-L1 modulates cytokine-dependent transcriptional regulation of p27(KIP1). Mol Cell Biol 2000, 20:9138-9148.

62. Stahl M, Dijkers PF, Kops GJ, Lens SM, Coffer PJ, Burgering BM, Medema RH: The forkhead transcription factor FoxO regulates transcription of p27Kip1 and Bim in response to IL-2. J Immunol 2002, 168:5024-5031.

63. Yang JY, Xia W, Hu MC: lonizing radiation activates expression of FOXO3a, Fas ligand, and Bim, and induces cell apoptosis. Int J Oncol 2006, 29:643-648.

64. Wang K, Li PF: Foxo3a regulates apoptosis by negatively targeting miR-21. J Biol Chem 2010, 285:16958-16966.

65. Mikse OR, Blake DC Jr, Jones NR, Sun YW, Amin S, Gallagher CJ, Lazarus P, Weisz J, Herzog CR: FOXO3 encodes a carcinogen-activated transcription factor frequently deleted in early-stage lung adenocarcinoma. Cancer Res 2010, 70:6205-6215.

66. Blake DC Jr, Mikse OR, Freeman WM, Herzog CR: FOXO3a elicits a pro-apoptotic transcription program and cellular response to human lung carcinogen nicotine-derived nitrosaminoketone (NNK). Lung Cancer 2010, 67:37-47.

67. Yang YC, Tang YA, Shieh JM, Lin RK, Hsu HS, Wang YC: DNMT3B overexpression by deregulation of FOXO3a-mediated transcription repression and MDM2 overexpression in lung cancer. $J$ Thorac Oncol 2014, 9:1305-1315.
68. Khoo KH, Verma CS, Lane DP: Drugging the $\mathrm{p} 53$ pathway: understanding the route to clinical efficacy. Nat rev Drug discov 2014, 13:217-236.

69. Yang JY, Zong CS, Xia W, Yamaguchi H, Ding Q, Xie X, Lang JY, Lai CC, Chang CJ, Huang WC, Huang H, Kuo HP, Lee DF, Li LY, Lien HC, Cheng X, Chang KJ, Hsiao CD, Tsai FJ, Tsai CH, Sahin AA, Muller WJ, Mills GB, Yu D, Hortobagyi GN, Hung MC: ERK promotes tumorigenesis by inhibiting FOXO3a via MDM2-mediated degradation. Nat Cell Biol 2008, 10:138-148.

70. Bhattacharya S, Ghosh MK: HAUSP, a novel deubiquitinase for Rb - MDM2 the critical regulator. FEBS J 2014, 281:3061-3078.

71. Landers JE, Cassel SL, George DL: Translational enhancement of mdm2 oncogene expression in human tumor cells containing a stabilized wild-type p53 protein. Cancer Res 1997, 57:3562-3568.

72. Iorio MV, Croce CM: microRNA involvement in human cancer. Carcinogenesis 2012, 33:1126-1133.

73. Fabbri M, Garzon R, Cimmino A, Liu Z, Zanesi N, Callegari E, Liu S, Alder H, Costinean S, Fernandez-Cymering C, Volinia S, Guler G, Morrison CD, Chan KK, Marcucci G, Calin GA, Huebner K, Croce CM: MicroRNA-29 family reverts aberrant methylation in lung cancer by targeting DNA methyltransferases 3A and 3B. Proc Natl Acad Sci U S A 2007 104:15805-15810.

74. Garzon R, Liu S, Fabbri M, Liu Z, Heaphy CE, Callegari E, Schwind S, Pang J, Yu J, Muthusamy N, Havelange V, Volinia S, Blum W, Rush L, Perrotti D, Andreeff M, Bloomfield CD, Byrd JC, Chan K, Wu LC, Croce CM, Marcucci G: MicroRNA-29b induces global DNA hypomethylation and tumor suppressor gene reexpression in acute myeloid leukemia by targeting directly DNMT3A and 3B and indirectly DNMT1. Blood 2009, 113:6411-6418.

75. Nguyen T, Kuo C, Nicholl MB, Sim MS, Turner RR, Morton DL, Hoon DS: Downregulation of microRNA-29c is associated with hypermethylation of tumor-related genes and disease outcome in cutaneous melanoma. Epigenetics 2011, 6:388-394

76. Chen Y, Min L, Zhang X, Hu S, Wang B, Liu W, Wang R, Gu X, Shen W, Lv H, Zou J, Xu X, Chen L: Decreased miRNA-148a is associated with lymph node metastasis and poor clinical outcomes and functions as a suppressor of tumor metastasis in non-small cell lung cancer. Oncol Rep 2013, 30:1832-1840.

77. Azizi M, Teimoori-Toolabi L, Arzanani MK, Azadmanesh K, Fard-Esfahani P, Zeinali S: MicroRNA-148b and microRNA-152 reactivate tumor suppressor genes through suppression of DNA methyltransferase- 1 gene in pancreatic cancer cell lines. Cancer Biol Ther 2014, 15(4):419-427.

78. Sandhu R, Rivenbark AG, Coleman WB: Loss of post-transcriptional regulation of DNMT3b by microRNAs: a possible molecular mechanism for the hypermethylation defect observed in a subset of breast cancer cell lines. Int J Oncol 2012, 41:721-732.

79. Ng EK, Tsang WP, Ng SS, Jin HC, Yu J, Li JJ, Rocken C, Ebert MP, Kwok TT, Sung JJ: MicroRNA-143 targets DNA methyltransferases 3A in colorectal cancer. Br J Cancer 2009, 101:699-706.

80. Lee JY, Jeong W, Lim W, Lim CH, Bae SM, Kim J, Bazer FW, Song G: Hypermethylation and post-transcriptional regulation of DNA methyltransferases in the ovarian carcinomas of the laying hen. Plos one 2013, 8:e61658.

81. Hong Q, Shao ZM: Ubiquitination/deubiquitination and acetylation/ deacetylation: making DNMT1 stability more coordinated. Acta Pharmacol Sin 2011, 32:139-140.

82. Du Z, Song J, Wang Y, Zhao Y, Guda K, Yang S, Kao HY, Xu Y, Willis J, Markowitz SD, Sedwick D, Ewing RM, Wang Z: DNMT1 stability is regulated by proteins coordinating deubiquitination and acetylation-driven ubiquitination. Sci Signal 2010, 3:ra80.

83. Huang J, Stewart A, Maity B, Hagen J, Fagan RL, Yang J, Quelle DE, Brenner C, Fisher RA: RGS6 suppresses Ras-induced cellular transformation by facilitating Tip60-mediated Dnmt1 degradation and promoting apoptosis. Oncogene 2013, doi: 10.1038/onc.2013.324

84. Peng L, Yuan Z, Ling H, Fukasawa K, Robertson K, Olashaw N, Koomen J, Chen J, Lane WS, Seto E: SIRT1 deacetylates the DNA methyltransferase 1 (DNMT1) protein and alters its activities. Mol Cell Biol 2011, 31:4720-4734

85. Kar S, Deb M, Sengupta D, Shilpi A, Parbin S, Torrisani J, Pradhan S, Patra S: An insight into the various regulatory mechanisms modulating human DNA methyltransferase 1 stability and function. Epigenetics 2012, 7:994-1007. 
86. Lin RK, Hsieh YS, Lin P, Hsu HS, Chen CY, Tang YA, Lee CF, Wang YC: The tobacco-specific carcinogen NNK induces DNA methyltransferase 1 accumulation and tumor suppressor gene hypermethylation in mice and lung cancer patients. J Clin Invest 2010, 120:521-532.

87. Hecht SS: Tobacco smoke carcinogens and lung cancer. J Nat/ Cancer Inst 1999, 91:1194-1210.

88. Kim DH, Nelson HH, Wiencke JK, Zheng S, Christiani DC, Wain JC, Mark EJ, Kelsey KT: p16(INK4a) and histology-specific methylation of CpG islands by exposure to tobacco smoke in non-small cell lung cancer. Cancer Res 2001, 61:3419-3424.

89. Kim DH, Kim JS, Ji Yl, Shim YM, Kim H, Han J, Park J: Hypermethylation of RASSF1A promoter is associated with the age at starting smoking and a poor prognosis in primary non-small cell lung cancer. Cancer Res 2003, 63:3743-3746.

90. Kim JS, Kim H, Shim YM, Han J, Park J, Kim DH: Aberrant methylation of the FHIT gene in chronic smokers with early stage squamous cell carcinoma of the lung. Carcinogenesis 2004, 25:2165-2171.

91. Hutt JA, Vuillemenot BR, Barr EB, Grimes MJ, Hahn FF, Hobbs CH, March TH, Gigliotti AP, Seilkop SK, Finch GL, Mauderly JL, Belinsky SA: Life-span inhalation exposure to mainstream cigarette smoke induces lung cancer in $\mathrm{B} 6 \mathrm{C} 3 \mathrm{~F} 1$ mice through genetic and epigenetic pathways. Carcinogenesis 2005, 26:1999-2009.

92. Vuillemenot BR, Hutt JA, Belinsky SA: Gene promoter hypermethylation in mouse lung tumors. Mol Cancer Res 2006, 4:267-273.

93. Pulling LC, Vuillemenot BR, Hutt JA, Devereux TR, Belinsky SA: Aberrant promoter hypermethylation of the death-associated protein kinase gene is early and frequent in murine lung tumors induced by cigarette smoke and tobacco carcinogens. Cancer Res 2004, 64:3844-3848.

94. Askari MD, Tsao MS, Schuller HM: The tobacco-specific carcinogen, 4-(methylnitrosamino)-1-(3-pyridyl)-1-butanone stimulates proliferation of immortalized human pancreatic duct epithelia through beta-adrenergic transactivation of EGF receptors. J Cancer Res Clin Oncol 2005, 131:639-648.

95. Laag E, Majidi M, Cekanova M, Masi T, Takahashi T, Schuller HM: NNK activates ERK1/2 and CREB/ATF-1 via beta-1-AR and EGFR signaling in human lung adenocarcinoma and small airway epithelial cells. Int $\mathrm{J}$ Cancer 2006, 119:1547-1552

96. Tsurutani J, Castillo SS, Brognard J, Granville CA, Zhang C, Gills JJ, Sayyah J, Dennis PA: Tobacco components stimulate Akt-dependent proliferation and NFkappaB-dependent survival in lung cancer cells. Carcinogenesis 2005, 26:1182-1195.

97. Sharma M, Chuang WW, Sun Z: Phosphatidylinositol 3-kinase/Akt stimulates androgen pathway through GSK3beta inhibition and nuclear beta-catenin accumulation. J Biol Chem 2002, 277:30935-30941.

98. Taketo MM: Shutting down Wnt signal-activated cancer. Nat Genet 2004, 36:320-322.

99. Li C, Ebert PJ, Li QJ: T cell receptor (TCR) and transforming growth factor beta (TGF-beta) signaling converge on DNA (cytosine-5)methyltransferase to control forkhead box protein 3 (foxp3) locus methylation and inducible regulatory T cell differentiation. J Biol Chem 2013, 288:19127-19139.

100. Lavoie G, St-Pierre Y: Phosphorylation of human DNMT1: implication of cyclin-dependent kinases. Biochem Biophys Res Commun 2011, 409:187-192.

101. Hervouet E, Lalier L, Debien E, Cheray M, Geairon A, Rogniaux H, Loussouarn D, Martin SA, Vallette FM, Cartron PF: Disruption of Dnmt1/PCNA/UHRF1 interactions promotes tumorigenesis from human and mice glial cells. Plos one 2010, 5:e11333.

102. Lavoie G, Esteve PO, Laulan NB, Pradhan S, St-Pierre Y: PKC isoforms interact with and phosphorylate DNMT1. BMC Biol 2011, 9:31.

103. Esteve PO, Chang Y, Samaranayake M, Upadhyay AK, Horton JR, Feehery GR, Cheng $X$, Pradhan S: A methylation and phosphorylation switch between an adjacent lysine and serine determines human DNMT1 stability. Nat Struct Mol Biol 2011, 18:42-48.

104. Matsusaka K, Funata S, Fukayama M, Kaneda A: DNA methylation in gastric cancer, related to and Epstein-Barr virus. World J Gastroenterol 2014, 20:3916-3926.

105. Tempera I, Lieberman PM: Epigenetic regulation of EBV persistence and oncogenesis. Semin Cancer Biol 2014, 26C:22-29.

106. Qiu X, Zhang L, Lu S, Song Y, Lao Y, Hu J, Fan H: Upregulation of DNMT1 mediated by $\mathrm{HBx}$ suppresses RASSF1A expression independent of DNA methylation. Oncol Rep 2014, 31:202-208.
107. Fang JY, Mikovits JA, Bagni R, Petrow-Sadowski CL, Ruscetti FW: Infection of lymphoid cells by integration-defective human immunodeficiency virus type 1 increases de novo methylation. J Virol 2001, 75:9753-9761.

108. Pion M, Jaramillo-Ruiz D, Martinez A, Munoz-Fernandez MA, Correa-Rocha R: HIV infection of human regulatory $T$ cells downregulates Foxp3 expression by increasing DNMT3b levels and DNA methylation in the FOXP3 gene. AIDS 2013, 27:2019-2029

doi:10.1186/2045-3701-4-46

Cite this article as: Lin and Wang: Dysregulated transcriptional and post-translational control of DNA methyltransferases in cancer. Cell \& Bioscience 2014 4:46.

\section{Submit your next manuscript to BioMed Central and take full advantage of:}

- Convenient online submission

- Thorough peer review

- No space constraints or color figure charges

- Immediate publication on acceptance

- Inclusion in PubMed, CAS, Scopus and Google Scholar

- Research which is freely available for redistribution

Submit your manuscript at www.biomedcentral.com/submit
C BioMed Central 